Review

\title{
Kidney Transplantation during the COVID-19 Pandemic: From Past through Present Time of Emerging Vaccine
}

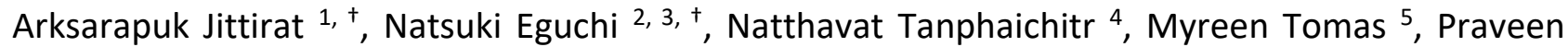
Gundelly ${ }^{5}$, Kai Zhao ${ }^{6}$, Leal Herlitz ${ }^{7}$, Yasolatha Chalicheemala ${ }^{1}$, Himabindu Yerneni ${ }^{1}$, Rachel C. Forbes $^{8}$, Beatrice P. Concepcion ${ }^{9}$, Ekamol Tantisattamo ${ }^{2,10,11,{ }^{*}}$

1. Department of Medicine, Division of Nephrology and Hypertension, University Hospitals Cleveland Medical Center, Case Western Reserve University, 11100 Euclid Avenue, Cleveland, Ohio, United States; E-Mails: Arksarapuk.Jittirat@UHhospitals.org; Yasolatha.Chalicheemala@UHhospitals.org; Himabindu.Yerneni@UHhospitals.org

2. Harold Simmons Center for Kidney Disease Research and Epidemiology, Division of Nephrology, Hypertension and Kidney Transplantation, Department of Medicine, University of California Irvine School of Medicine, Orange, California, United States; E-Mails: neguchi@hs.uci.edu; etantisa@hs.uci.edu

3. Division of Kidney and Pancreas Transplantation, Department of Surgery, University of California Irvine School of Medicine, Orange, California, United States

4. Department of Nephrology, Americare Kidney Institutes /Cleveland Clinic Akron General Medical Center, Akron, Ohio, United States; E-Mail: tomntan@icloud.com

5. Department of Medicine, Division of Infectious Disease and HIV, University Hospitals Cleveland Medical Center, Case Western Reserve University, Cleveland, Ohio, United States; E-Mails: Myreen.tomas@uhhospitals.org; Praveen.Gundelly@UHhospitals.org

6. Department of Surgery, Division of Kidney and Pancreas Transplantation, University Hospitals Cleveland Medical Center, Case Western Reserve University, Cleveland, Ohio, United States; EMail: Kai.Zhao@UHhospitals.org

7. Department of Anatomic Pathology, Cleveland Clinic, Cleveland, Ohio, United States; E-Mail: herlitl@ccf.org

8. Department of Surgery, Division of Kidney and Pancreas Transplantation, Vanderbilt University Medical Center, Nashville, Tennessee, United States; E-Mail: rachel.forbes@vumc.org

9. Department of Medicine, Division of Nephrology and Hypertension, Vanderbilt University Medical Center, Nashville, Tennessee, United States; E-Mail: beatrice.p.concepcion@vumc.org

10. Nephrology Section, Department of Medicine, Tibor Rubin Veterans Affairs Medical Center, Veterans Affairs Long Beach Healthcare System, Long Beach, California, United States

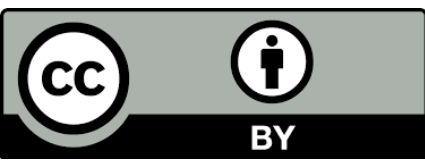

(C) 2022 by the author. This is an open access article distributed under the conditions of the Creative Commons by Attribution License, which permits unrestricted use, distribution, and reproduction in any medium or format, provided the original work is correctly cited. 
11. Multi-Organ Transplant Center, Section of Nephrology, Department of Internal Medicine, William Beaumont Hospital, Oakland University William Beaumont School of Medicine, Royal Oak, Michigan, United States

† These authors contributed equally to this work.

* Correspondence: Ekamol Tantisattamo; E-Mail: etantisa@hs.uci.edu

Academic Editors: Sok Cheon Pak and Soo Liang Ooi

Special Issue: Complementary, Traditional, and Integrative Medicine for COVID-19

OBM Integrative and Complementary Medicine 2022, volume 7 , issue 1

doi:10.21926/obm.icm.2201007
Received: May 02, 2021

Accepted: January 24, 2022

Published: February 07, 2022

\begin{abstract}
The novel coronavirus disease 2019 (COVID-19) pandemic has significantly impacted kidney transplantation worldwide. The rate of kidney transplantation decreased during the peak of the COVID-19 pandemic, especially living donor kidney transplantation. Kidney transplant recipients are at high risk of developing severe complications from COVID-19 due to underlying comorbidities and immunosuppressed status. Management of immunosuppression, including the induction therapy and maintenance immunosuppressive regimen, has been modified at many transplant centers during the pandemic. In severe acute respiratory virus syndrome coronavirus 2 (SARS-CoV-2) infected kidney transplant recipients, the immunosuppression is usually reduced. The acute rejection treatment is usually individualized based on the risks and benefits. Several COVID-19 therapies have received emergency use authorization to prevent the progression of COVID-19 severity. Use of oral antiviral therapies is faced with challenges in terms of drug-drug interaction, drug efficacy, and lack of data in the transplant population. For COVID-19 prophylaxis in kidney transplant recipients, the effectiveness of COVID-19 vaccines is lower compared to the general population. Pre-exposure prophylaxis with a long-acting antibody combination may be an adjunct strategy for vaccination in kidney transplant recipients or those for whom COVID-19 vaccination is not contraindicated. Post-exposure prophylaxis remains to be studied. Further studies are necessary to establish standard guidelines of immunosuppressive management in kidney transplant recipients diagnosed with COVID-19 and to better understand the outcomes and adverse drug reactions of the therapeutic and prophylactic modalities including vaccination in this high-risk population.
\end{abstract}

\title{
Keywords
}

COVID-19; COVID vaccine; Delta variant; immunosuppressive management; kidney transplant; Omicron variant; rejection; SARS-CoV-2

\section{Introduction: From the Beginning 2022 of the COVID-19 Pandemic}

At the end of 2019, the novel coronavirus disease 2019 (COVID-19) resulting from severe acute respiratory virus syndrome coronavirus 2 (SARS-CoV-2) appeared in Wuhan, People's Republic of 
China. Common symptoms were fever, loss of taste or smell, flu-like symptoms, nausea, vomiting, and diarrhea. The virus caused pneumonia, shock, multi-organ failure, thromboembolism, and severe acute respiratory distress syndrome (ARDS). COVID-19 rapidly spread throughout China becoming a pandemic. The disease was initially reported to the World Health Organization (WHO) on December 31, 2019 [1]. WHO declared the COVID-19 outbreak a public health emergency of international concern, WHO's highest level of alarm, on January 30, 2020. SARS-CoV-2 continued to spread across several countries and was eventually classified as a global pandemic on March 11, 2020. As of January 14,2022 , the WHO reported $318,648,834$ confirmed cases and $5,518,343$ confirmed deaths [2]. On January 15, 2022, the Centers for Disease Control and Prevention (CDC) also reported 65,159,554 total cases and 847,577 total deaths in the United States [3].

The virus causing COVID-19 constantly mutates and new variants have been identified in different countries including the first variant B.1.1.7 in the United Kingdom, variant B.1.351 in South Africa, variant P.1 in Brazil, variant B.1.617.2 (Delta) in India, and the most recent variant B.1.1.529 (Omicron) in South Africa [4].

Approximately $80 \%$ of patients recover from the disease without needing hospital admission. However, $15 \%$ of patients become seriously ill requiring supplemental oxygen and around $5 \%$ of patients become critically ill enough requiring admission to the intensive care unit. Patients with underlying chronic kidney disease (CKD) and immunocompromised states such as in kidney transplant patients are at increased risk for severe illnesses from COVID-19. Acute kidney injury (AKI), end-stage kidney disease (ESKD) or kidney allograft failure can occur which may require kidney replacement therapy (KRT). While several studies demonstrated poor outcomes of COVID-19 in kidney transplant recipients during the initial period of the pandemic, severe of those were limited in study designs and lack of control groups. In this article, we review and discuss the evidence on the impact of COVID-19 on kidney transplantation in terms of access in transplantation, transplantrelated outcomes and complications, changes in clinical practice among transplant communities including our experiences, and future preventive strategies including COVID-19 vaccinations.

\section{Impact of COVID-19 on Kidney Transplantation in 2022}

\subsection{Pre-Transplant Phase: Kidney Transplant Evaluation and Living Donor Evaluation}

During the early part of the COVID-19 pandemic, the rate of kidney transplants decreased by $51 \%$ [5]. At the peak of the pandemic in early 2020, some transplant centers placed the living donor transplant programs on hold temporarily, considering it as elective surgery. According to the United Network for Organ Sharing (UNOS) data, the number of kidney transplants profoundly decreased between March and April 2020 with a gradual increase back to normal rate by June 2020 after the hospital resources were in place. Over the past 2 years since the COVID-19 pandemic emerged, compared to the total number of kidney transplantations in the United States in 2019, kidney transplantation decreased in 2020 then increased in 2021 (23,401 vs. 22,817 vs. 24,669). This resulted from an increase in deceased donor kidney transplantations every year from 2019 to 2021 $(16,534$ vs. 17,583 vs. 18,699$)$, while living donor kidney transplantation significantly decreased in $2020(5,234)$ and slightly increased in $2021(5,970)$ but not equal to $2019(6,867)$ [6].

Waitlisted kidney transplant candidates, who mostly receive in-center hemodialysis, were at risk for contracting COVID-19 given the necessity to undergo hemodialysis $2-4$ times/week with difficulty performing social distancing. This may have led to a spike in the inactivation of patients on 
the kidney transplant waiting list during the same time frame. The kidney transplant candidates on the waiting list who were diagnosed with COVID-19 were placed on status 7 (inactive) until they recovered from COVID-19. Although immunosuppressed status after kidney transplantation intuitively increases the risk for contracting and having severe complications from COVID-19, the waitlisted patients who were diagnosed with COVID-19 were more likely to require hospitalization (82\%) and were at a higher risk of mortality compared to kidney transplant recipients [7]. The majority of waitlisted kidney transplant candidates had several significant medical comorbidities that were known to be associated with increased risk of COVID-19-related mortality. The longer the dialysis vintage, the greater the mortality due partly to uremic and dialysis complications. Waitlist kidney transplant candidates are generally healthier than dialysis patients who are not transplant candidates and kidney transplantation still improves patient survival [8]. Therefore, weighing between potential complications from kidney transplantation related to COVID-19 and survival benefit from this life-saving surgery should be carefully considered. Kidney transplantation should be postponed in candidates with active COVID-19. The appropriate time to transplant candidates after COVID-19 symptoms have resolved may need to be individualized. A negative SARS-CoV-2 PCR from the respiratory tract before transplantation is recommended; however, some centers require two negative tests for 24 hours apart. For disease-free candidates with prolonged positive PCR tests for viral RNA, the decision for kidney transplantation should be individualized [9].

Currently, the Centers for Medicare and Medicaid Services (CMS) issued guidance [10] that identified organ transplants as Tier $3 \mathrm{~b}$ procedures that should not be postponed. CMS also recommended that hospitals continue to provide organ procurement organization (OPO) staff access to hospital facilities for deceased donor organ recovery.

\subsection{Perioperative Phase: Induction Immunosuppressive Management}

To date, it is unclear whether SARS-CoV-2 detected outside the respiratory tract is transmissible by non-lung transplantation. However, appropriate precautions need to be taken during the perioperative phase of transplantation.

Potential kidney transplant recipients admitted to the hospital should be screened for COVID-19 symptoms as well as for the history of recent travel and direct contact with COVID-19 patients. Further, only potential recipients who test negative for the SARS-CoV-2 nucleic acid amplification test (NAAT) may proceed with kidney transplantation and receive induction immunosuppression. The deceased donors are screened with similar testing prior to organ procurement. The Organ Procurement and Transplantation Network (OPTN) recommended viral testing of at least one sample from the respiratory tract by NAAT for SARS-CoV-2 be performed within 3 days of procurement. Some experts recommend a second viral test be performed 24-hours after the initial test and within 24-48 hours of procurement when feasible. Deceased donors need to be carefully selected to avoid the risk of transplanting SARS-CoV-2 infected allografts into the recipients. Living solid organ donors are counseled on strategies to prevent infection and monitored for exposures and symptoms in the 14 days before a scheduled transplant. Potential living donors are also tested for SARS-CoV-2 prior to surgery. The OPTN also recommends that all living donors should be tested at least once with a sample from the upper respiratory tract by NAAT for SARS-CoV-2 as close to donation as possible but no longer than 3 days before surgery. For living donors who were previously known to have had COVID-19, the American Society of Transplantation (AST) recommends considering proceeding to transplant if repeat NAAT test is negative or if symptoms have resolved and if the initial COVID- 19 infection occurred between 21- 90 days prior to donation, 
irrespective of repeat NAAT results. We usually delay transplant surgery for asymptomatic living donors with a known exposure history within the previous 14 days.

Due to the effectiveness of COVID vaccines in the general population and the increased risk of worse clinical outcomes of COVID-19 in transplant recipients, the COVID-19 Treatment Guidelines Panel recommends vaccination for potential transplant candidates, potential donors, and recipients as per expert opinion. AST also recommends strongly encouraging living donors to be fully vaccinated for COVID-19, preferably with vaccine completion at least 2 weeks in anticipation of donation.

There is no definite international consensus on the choice of induction immunosuppressive therapy for kidney transplantation during the COVID-19 pandemic. The standard induction regimen consists of methylprednisolone and an antibody such as rabbit antithymocyte globulin (rATG), alemtuzumab, and basiliximab. Among patients at increased risk of rejection, the administration of rATG is preferred. Many kidney transplant centers that primarily use rATG have reduced the total dosage of the induction regimen from $6 \mathrm{mg} / \mathrm{Kg}$ to $4.5 \mathrm{mg} / \mathrm{Kg}$. The use of non-T cell depleting agent, IL-2 receptor antagonists (basiliximab), as an induction therapy has also been increased during the COVID pandemic to avoid the T cell depleting effect of rATG. However, basiliximab may be generally limited for transplant candidates with low immunological risk during the COVID-19 surge since the risk of acute rejection after transplant without $T$ cell depleting agents in high immunological risk candidates may inadvertently escalate immunosuppression for acute rejection therapy. After kidney transplant surgery is performed, patients are started on standard immunosuppressive maintenance medications, including calcineurin inhibitor (CNI), mycophenolate mofetil (MMF) with or without prednisone based on the standard protocols at each kidney transplant center.

\subsection{Maintenance Immunosuppressive Management during the Pandemic}

Kidney transplant patients admitted with COVID-19 have shown higher early mortality compared to the general population with a more rapid clinical progression of the disease [11]. Pereira et al. analyzed 90 solid organ transplant patients at two centers during the first 3 weeks of the outbreak in New York City. In this initial cohort study, transplant recipients with COVID-19 appeared to have more severe outcomes such as ICU admission and death although testing limitations likely led to an underestimation of mild or asymptomatic cases. As the outbreak unfolds, COVID-19 has shown the potential to severely impact solid organ transplant recipients [12]. A retrospective study by Akalin et al. identified 36 kidney transplant recipients who tested positive for COVID-19. They found that kidney-transplant recipients with COVID-19 had less fever as an initial symptom, lower CD3, CD4, and CD8 cell counts, and more rapid clinical progression than patients with COVID-19 in the general population. A very high early mortality among kidney-transplant recipients with COVID-19 was also seen. The authors reported $28 \%$ mortality at 3 weeks compared to the reported $1 \%$ to $5 \%$ mortality among patients with COVID-19 in the general population. They also reported $8-15 \%$ mortality among patients with COVID-19 who were older than 70 years old [13]. The higher number of patients with very low CD3, CD4, and CD8 cell counts indirectly supports the need to decrease doses of immunosuppressive agents in patients with COVID-19, especially in those who have recently received rATG which decreases all T-cell subsets for many weeks. Husain et.al. reported their experience in 41 outpatient kidney transplant recipients with known or suspected COVID-19. Of these patients, $32 \%$ required hospitalization with a median of 8 days after symptom onset and $56 \%$ had symptom resolution with a median of 12 days from onset without requiring hospital admission. Patients who required hospitalization had higher baseline creatinine. A total of 23 patients (56\%) 
had a reduction in their immunosuppression regimen, including $42 \%$ of suspected and $82 \%$ of patients with confirmed cases. The remaining 18 (44\%) had no change in their regimen [14].

Available evidence related to maintenance immunosuppressive medications and clinical outcomes in kidney transplant recipients may limit generalizability from different phases of COVID19 pandemic among each study and retrospective nature of the studies.

In summary, for kidney transplant recipients who do not have COVID-19, the continuation of the same maintenance anti-rejection medications regimen may be utilized with close monitoring of patients via telehealth and educating patients to notify transplant providers once developing possible symptoms of COVID-19. For kidney transplant patients who have active COVID-19, we suggest reducing immunosuppression especially in patients requiring hospital admission. The first step is to stop the antimetabolite (azathioprine or mycophenolate). Corticosteroid is usually increased as a part of COVID-19 treatment. We recommend lowering the goal of a 12-hour tacrolimus/cyclosporine/mammalian target of rapamycin (mTOR) inhibitor target trough level to 3 - $5 \mathrm{ng} / \mathrm{mL}$ with dosing modification based on the risk of acute rejection and worsening COVID-19 or potential new-onset opportunistic infections. $\mathrm{CNI}$ and mTOR inhibitor should be discontinued in patients with severe disease who require ICU admission or mechanical ventilation [15-18]. Experimental data suggest that certain immunosuppressive agents such as mTOR inhibitors may have some biological activity against SARS-CoV-2, but additional studies are warranted [19].

\subsection{Acute Rejection Treatment}

It is challenging to manage acute rejection in kidney transplant recipients during the COVID-19 pandemic. There is no consensus guideline and the acute rejection treatment course should be individualized after weighing the risks of contracting COVID-19 or worsening COVID-19 and the benefits of reversing or recovering acute rejection from escalating timely immunosuppressive medications. We generally do not treat acute rejection in patients who have active COVID-19; however, the decision and the optimal time to initiate acute rejection therapy may need to be justified based on severity and clinical course of COVID-19 and risk of allograft loss or possible salvageability. For patients with acute rejection, who do not have COVID-19, we proceed with the treatment of acute rejection. Over-immunosuppression to minimize the risk of the development of severe COVID-19 is recommended [9]. Several causes of worsening allograft function in kidney transplant recipients with COVID-19 may mimic acute allograft rejection and a presumptive diagnosis of acute rejection may lead to a therapy that consequently causes overimmunosuppression. Although there are non-invasive investigations to determine the possibility of acute kidney allograft rejection such as donor-derived cell-free DNA, allograft biopsy should be performed to confirm the diagnosis unless there is a contraindication for the biopsy. We also consider withholding rejection treatment in the patients with progressively declining allograft function toward failing kidney allograft and maintenance immunosuppressive medications should be carefully managed; although there is no consensus guideline for immunosuppressive medication management in this setting [20].

\section{Complications Associated with COVID in Kidney Transplant Patients}

\subsection{Kidney Complications Associated with COVID}

\subsubsection{Acute Kidney Injury (AKI)}

Similar to the non-transplant population, AKI is a common complication in kidney transplant recipients with COVID-19. The etiologies of AKI in kidney transplant recipients can result from 
multifactorial conditions including hemodynamic instability, effective circulatory volume depletion, and cytokine storm from sepsis resulting in acute tubular necrosis. Renal ischemia or direct viral cytopathic effects on tubular and endothelial cells may lead to AKI (Figure 1). However, a reported case of a kidney transplant recipient with severe COVID-19 complicated by AKI requiring continuous kidney replacement therapy with subsequent failure from kidney allograft infarction did not reveal evidence of SARS-CoV-2 in the explanted kidney allograft [21]. In addition, acute rejection may occur in the setting of reduced immunosuppression.

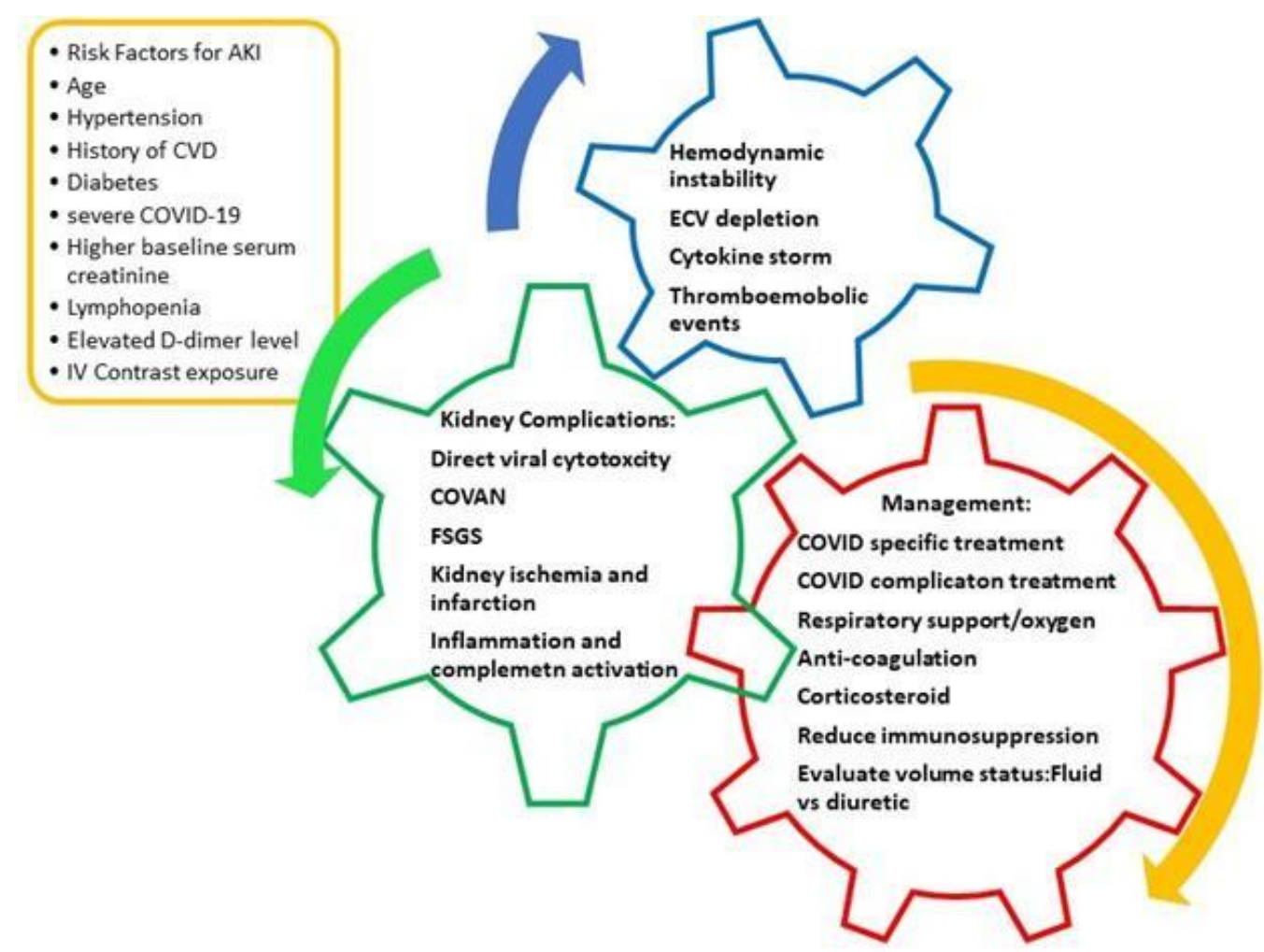

Figure 1 Kidney complications associated with COVID-19 and management. Abbreviations: Acute Kidney Injury (AKI), Effective circulatory volume (ECV), Cardiovascular diseases (CVD), Coronavirus associated nephropathy (COVAN), Intravenous (IV).

For non-transplant patients, data from a national cohort study of 5,216 US veterans who were hospitalized with COVID-19 showed that $32 \%$ of patients had AKI, $12 \%$ of patients received kidney replacement therapy, and $47 \%$ of patients did not recover to baseline serum creatinine by discharge. Older age, African American race, male gender, obesity, diabetes, hypertension, and lower glomerular filtration rate were significant predictors of AKI during hospitalization with COVID19. AKI was associated with higher mechanical ventilation use, a longer hospital stay, a higher risk of health care resource utilization, and death [22]. Supporting these findings, Cheng et al. demonstrated that severe disease, higher baseline serum creatinine, lymphopenia, and elevated Ddimer level were factors associated with a higher risk of AKI. In-hospital mortality among patients with AKI stage 1, stage 2, and stage 3 was $62 \%, 77 \%$, and $80 \%$, respectively [23]. Robbins-Juarez et al. performed a meta-analysis on approximately 13,000 patients, the majority of whom were hospitalized. The incidence of AKI was $17 \%$ (range 0.5 to $80 \%$ ), and approximately $5 \%$ of patients required KRT [24]. Gupta et al. published a multicenter cohort study of 3,099 critically ill adults with 
COVID-19 admitted to intensive care units at 67 hospitals across the United States. Of those patients who survived to discharge, $34 \%$ were dialysis-dependent at the time of discharge and more than one-half of those patients remained dialysis-dependent two months after discharge. It is unclear if KRT dependence is related to the severity of critical illness or the specific pathophysiology related to COVID-19. Long-term outcomes among patients requiring KRT in the setting of COVID-19 have not been studied [25].

For kidney transplant recipients, the incidence of AKI appeared greater than those of nontransplant recipients [15]. A retrospective study by Carvedi et al. identified and analyzed data from 144 hospitalized adult kidney transplant recipients at 12 transplant centers in the United States, Italy, and Spain who tested positive for COVID-19 from the Post-Transplant Glomerular Diseases (TANGO) International Transplant Consortium. Therapeutic management included antimetabolite withdrawal (68\%), CNI withdrawal (23\%), hydroxychloroquine (71\%), antibiotics (74\%), tocilizumab (13\%), and antivirals (14\%). During a median follow-up period of 52 days, AKI occurred in 52\%, with respiratory failure requiring intubation in $29 \%$. The mortality rate was $32 \%$. The 46 patients who died were older, had lower lymphocyte counts, and lower estimated glomerular filtration rate levels. These patients had higher serum lactate dehydrogenase, procalcitonin, and interleukin- 6 levels [26].

\subsubsection{Coronavirus-Associated Nephropathy (COVAN)}

The kidney biopsy findings in patients with COVID-19 are diverse, but the most common findings reported to date include acute tubular injury and collapsing glomerulopathy [27]. Collapsing glomerulopathy has been found to occur in patients with high-risk APOL1 genotypes (Figure 2). This is of potential significance in the kidney transplant setting as the APOL1 genotype of the donor may increase the underlying susceptibility for renal injury in kidney transplant patients who become infected with COVID-19. Kudose et al. included 3 allograft specimens in their study of 17 patients who had renal biopsies in the setting of COVID-19. One of these allografts shows grade $2 \mathrm{~A}$ acute cellular rejection, one showed acute tubular injury and one showed cortical infarction [27].

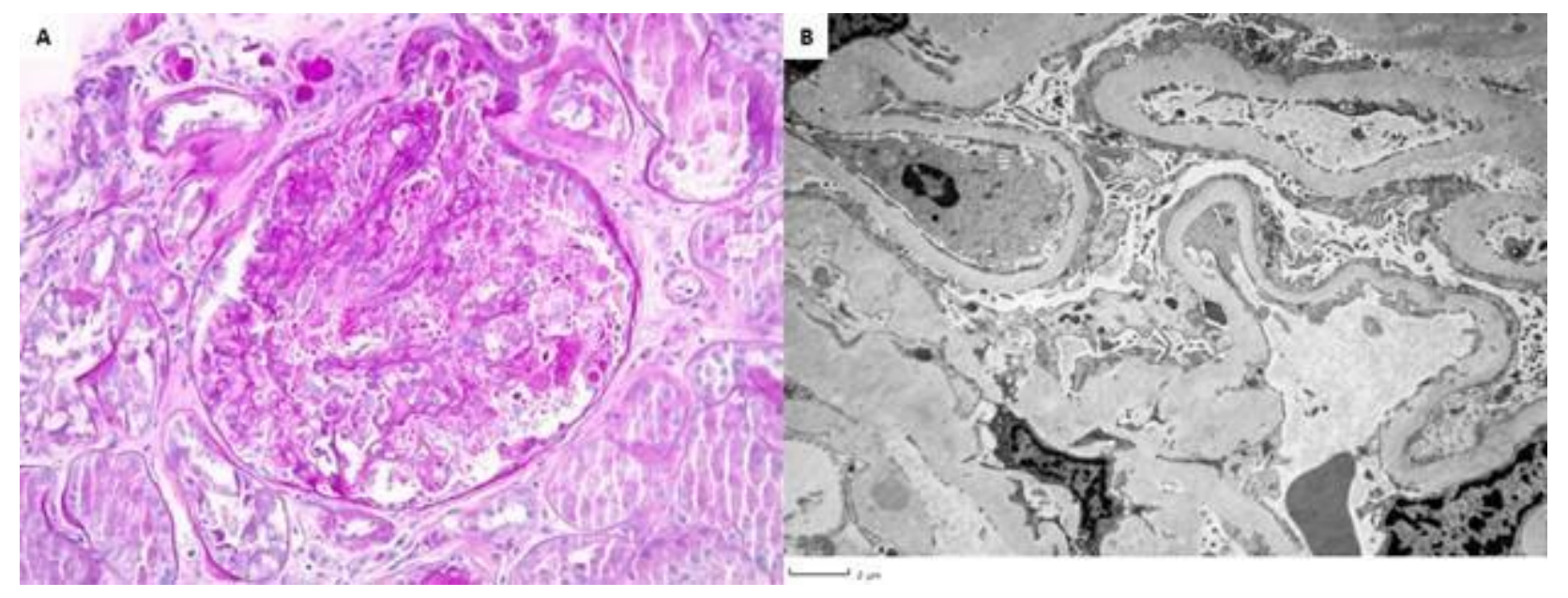

Figure 2 Kidney pathology of coronavirus associated nephropathy. Collapsing glomerulopathy. Periodic Acid Schiff staining (panel A) highlights the collapse of the glomerular tuft and hyperplasia of glomerular epithelial cells containing large protein resorption droplets. Electron microscopy shows diffuse podocyte foot process effacement, consistent with a podocytopathy (panel B). 


\subsubsection{Kidney Infarction}

There are several case reports of kidney and other abdominal visceral organ infarction with successful treatment with anticoagulation in non-transplanted patients diagnosed with COVID-19 $[28,29]$. There is one reported case of kidney infarction in a kidney transplant recipient who subsequently lost the kidney allograft [30] and a recently reported case of kidney allograft infarct confirmed by histopathology from explanted allograft [21].

SARS-CoV-2 can infect endothelial cells by binding to the angiotensin-converting enzyme 2 (ACE2) cellular receptors using the viral spike protein. Viral entry leads to endothelial cell dysfunction. The downregulation of ACE2 results in increased Angiotensin-II (Ang II) which binds angiotensin II type 1 receptor (AT1R) causing inflammation, fibrosis, vasoconstriction, hypofibrinolysis, hypercoagulable state, and endothelial cell death [31]. SARS-CoV-2-induced platelet activation may also contribute to thrombus formation and inflammatory responses in COVID-19 patients [32]. Kidney infarction can occur as a consequence of the mechanisms mentioned above and through disseminated intravascular coagulation.

\subsection{Extra-Renal Complications Associated with COVID}

Kidney transplant patients also exhibit similar extra-renal manifestations as the general population. Since SARS-CoV-2 can bind ACE2 receptors and infect cells, organs that have high expression of ACE2 receptors such as lungs, kidneys, gastrointestinal tract, liver, vascular endothelial cells, and arterial smooth muscle cells are more often infected by SARS-COV-2 [33]. Among all organ systems, the respiratory system is most commonly affected. In severe cases, patients may have superimposed bacterial pneumonia, acute hypoxic respiratory failure, ARDS, pulmonary embolism, and death. When the virus infects endothelial cells of coronary vessels, it may cause myocardial dysfunction, arrhythmias, and acute coronary syndrome. Infection of other organs may result in gastrointestinal complaints, hepatocellular injury, ocular symptoms, thromboembolic events, pulmonary hypertension, cor pulmonale, and dermatologic manifestations. Neurologic complications such as encephalopathy, ischemic stroke, intracerebral hemorrhage, hyposmia, hypogeusia, acute myelitis, Guillain-Barré syndrome, and Bell's palsy have been reported. Prolonged viral shedding, prolonged lymphopenia, transient IgM and IgG hypogammaglobulinemia can occur [34, 35]. Lastly, COVID-19 patients may also suffer from psychological impacts due to post-traumatic stress, confusion, anger, alcohol abuse or dependency, and depression due to prolonged quarantine.

\section{Treatment of COVID in Kidney Transplant Recipients}

In general, the management of COVID-19 infection is the same for transplant recipients as it is for the general population. Clinicians must be vigilant, however, in monitoring for potential drugdrug interactions, toxicities, and dosage adjustments. There have been rapid changes and development in the area of therapeutics for COVID-19 infection. 


\subsection{COVID Specific Treatment}

\subsubsection{Glucocorticoids}

In the early days of the pandemic, the use of corticosteroids was discouraged [36]. Subsequent multiple randomized controlled trials have suggested that dexamethasone $(6 \mathrm{mg}$ once daily for up to 10 days) reduces mortality in hospitalized patients with severe COVID-19 infection [37, 38]. The Randomised Evaluation of COVID-19 Therapy (RECOVERY) collaborative group demonstrated that glucocorticoids play a role in the modulation of inflammation-mediated lung injury and thereby reduce progression to respiratory failure and death. The study showed that in patients hospitalized with COVID-19, the use of dexamethasone resulted in lower 28-day mortality in those receiving either invasive mechanical ventilation or oxygen at randomization but not in those receiving no respiratory support [39]. Therefore, it is recommended to start dexamethasone (6 mg once daily up to 10 days) or other glucocorticoids at equivalent doses for COVID-19 patients requiring supplemental oxygen or mechanical ventilation.

Information regarding the impact of dexamethasone for COVID-19 treatment in kidney transplant recipients is not available at this time. Transplant patients will likely benefit from dexamethasone for the reduction of inflammation and acute rejection prevention. The risks of using dexamethasone including superimposed bacterial infection, fungal infection, and viral reactivation in kidney transplant recipients need to be taken into consideration.

\subsubsection{Hydroxychloroquine and Chloroquine}

On June 15, 2019, the United States (U.S.) Food and Drug Administration (FDA) revoked the emergency use authorization (EUA) that allowed for chloroquine phosphate and hydroxychloroquine sulfate donated to the Strategic National Stockpile to be used to treat certain hospitalized patients with COVID-19. The agency determined that the legal criteria for issuing the EUA were no longer met. Based on its ongoing analysis of the EUA and emerging scientific data, the FDA determined that chloroquine and hydroxychloroquine are unlikely to be effective in treating COVID-19 for the authorized use in the EUA. Additionally, in light of ongoing serious cardiac adverse events and other potentially serious side effects, the known and potential benefits of chloroquine and hydroxychloroquine no longer outweigh the known and potential risks for the authorized use [40].

The use of hydroxychloroquine in kidney transplant recipients is not recommended given the lack of proven benefits and potential drug interaction with CNIs which may cause prolonged QTC interval and dysrhythmia.

\subsubsection{Remdesivir}

Remdesivir, a nucleotide analog that inhibits viral RNA-dependent RNA polymerase, is the only antiviral approved by the U.S. FDA for the treatment of COVID-19 [41]. Remdesivir has been shown to reduce time to clinical improvement, but it has not been shown to provide mortality benefit [42, 43]. Given the active metabolite use of remdesivir is renally excreted and patients with stage 4 CKD were excluded from clinical trials, remdesivir is not recommended among patients with estimated glomerular filtration rate (eGFR) $<30 \mathrm{~mL} / \mathrm{min}$ per $1.73 \mathrm{~m}^{2}$ [44]; however, there was no significant difference in the incidence of AKI in COVID-19 patients treated with remdesivir between those with eGFR $<30$ and $\geq 30 \mathrm{ml} / \mathrm{min} / 1.73 \mathrm{~m}^{2}[45]$.

Remdesivir has been shown to be safe in transplant recipients. A multi-center cohort using data from the Spanish registry comprising dialysis and kidney transplant patients with a confirmed 
diagnosis of COVID-19 started on March 18, 2020 (S.E.N. COVID-19 registry) demonstrated renal and hepatic safety and tolerability of remdesivir therapy in kidney transplant recipients with COVID19. Among 51 kidney transplant recipients enrolled in this study, mean eGFR was $53.8 \pm 18.7$ $\mathrm{ml} / \mathrm{min} / 1.73 \mathrm{~m}^{2}$ and only 2 patients (3.9\%) had eGFR $<30 \mathrm{ml} / \mathrm{min} / 1.73 \mathrm{~m}^{2}$ [46]. Another singlecenter retrospective cohort including 245 transplant recipients with COVID-19 (58\% with kidney transplants) revealed that 102 patients (42\%) who received remdesivir therapy had a significant reduction of the length of hospitalization in the hospital and the intensive care unit and mortality rates compared to patients receiving high-dose corticosteroids. There was no significant difference in clinical complications such as bacterial coinfections, cardiovascular and gastrointestinal adverse reactions, and liver or kidney dysfunctions between remdesivir and other therapies. In this study, patients with eGFR $<30 \mathrm{ml} / \mathrm{min} / 1.73 \mathrm{~m}^{2}$ also received the same dose of remdesivir as those with eGFR $\geq 30 \mathrm{ml} / \mathrm{min} / 1.73 \mathrm{~m}^{2}$ [47].

\subsubsection{Convalescent Plasma}

Convalescent plasma has been used in the treatment of respiratory viruses dating back to the Spanish flu global pandemic of 1918 [48]. The proposed mechanism of action of convalescent plasma is through direct neutralization of the virus, control of cytokine storm, and immunomodulation of a hypercoagulable state [49]. Retrospective studies and randomized clinical trials suggest that transfusion of plasma with high antibody levels is more beneficial when given to patients within 3 days of COVID- 19 diagnosis who do not require mechanical ventilation. Based on published reports, convalescent plasma is safe and well-tolerated. There is a theoretical risk of antibody-dependent enhancement associated with plasma transfusion for transplant patients. A case series of 13 solid organ transplant recipients (5 kidney transplant recipients) revealed that 8 patients (62\%) could deescalate oxygenation support by day 7 post-convalescent plasma, 9 (69\%) patients were discharged, 1 patient (7\%) remained hospitalized, and 3 patients (23\%) died [50]. Another case series including 2 kidney transplant, 1 lung transplant, and 1 chronic myelogenous leukemia patients showed that all patients had clinical improvement after COVID-19 convalescent plasma administration without a transfusion reaction [51]. Further studies are required to investigate the efficacy and safety of convalescent plasma as either primary or adjunctive therapy for COVID-19. According to the most recent updated COVID-19 Treatment Guidelines 2021 by the National Institutes of Health (NIH), there is insufficient evidence to either recommend or against the use of convalescent plasma in patients with impaired humoral immunity [52]. However, thus far, there is no reported significant evidence of rejection related to the use of convalescent plasma kidney transplant recipients $[50,51]$.

\subsubsection{Monoclonal Antibodies}

Monoclonal antibodies differ from convalescent plasma by acting singularly on a predetermined target [53]. The monoclonal antibody regimens bamlanivimab and the combinations of bamlanivimab/etesevimab and casirivimab/imdevimab target the receptor-binding domain of the SARS-CoV-2 spike protein, blocking viral entry into host cells. All three regimens were given EUA by the U.S. FDA for the treatment of non-hospitalized patients with mild to moderate COVID-19 infection who are at high risk for progression to severe disease. Although COVID-19 positive patients receiving bamlanivimab early after the onset of the symptoms as an outpatient had lower 30-day hospitalization [54] as well as those with high risk (elderly, African American, Native American, and/ or Hispanic/Latino ethnicity, obese, and co-morbidities including hypertension, diabetes, coronary artery disease, chronic lung diseases, CKD, immunosuppressed) receiving casirivimab/imdevimab or bamlanivimab showed a reduction in 30-day hospitalization and COVID-19-related mortality [55], 
the EUA for bamlanivimab and bamlanivimab/etesevimab have since been withdrawn due to concerns for reduced efficacy with the emergence of SARS-CoV-2 viral variants [56-58].

Several single-center case series have been published on the use of monoclonal antibodies for the treatment of mild to moderate COVID-19 in the solid organ transplant population [59-61]. In the largest series published, Yetmar and colleagues report on 73 solid organ transplant recipients (56.2\% kidney recipients) who were treated with monoclonal antibodies, $75.3 \%$ of whom received bamlanivimab monotherapy. The 28 -day hospitalization rate post-infusion was $12.3 \%$, none required mechanical ventilation and there were no deaths. Monoclonal antibody therapy in this study appeared to be well-tolerated [59]. In another case series, Dhand and colleagues report on 25 solid organ transplant recipients treated with casirivimab/imdevimab, none of whom experienced progression of symptoms or required hospitalization [60].

Sotrovimab is another human neutralizing monoclonal antibody with activity against the SARSCoV-2 virus and authorized for use under the EUA for the treatment of mild-to-moderate COVID-19 in adults and pediatric patients (12 years of age and older weighing at least $40 \mathrm{~kg}$ ), and who are at high risk for progression to severe COVID-19 [62]. Sotrovimab is shown in pre-clinical data to have activity against all currently tested variants of concern and interest of the SARS-CoV-2 virus as defined by WHO, plus others, including but not limited to Delta (B.1.617.2), Delta Plus (AY.1 or AY.2), $\mathrm{Mu}$ (B.1.621) and Omicron (B.1.1.529) [63].

Taken together, the outcomes of these initial reports appear favorable. However, a prospective randomized controlled study that evaluates currently approved monoclonal antibodies in the treatment of mild to moderate COVID-19 in the solid organ transplant population is warranted to make any definitive conclusions regarding the efficacy and safety of this therapy.

\subsubsection{Anti-interleukin (IL)-6 Receptor Monoclonal Antibodies}

Anti-interleukin (IL)-6 receptor monoclonal antibodies such as tocilizumab and sarilumab are FDA-approved treatments for rheumatologic disorders and chimeric antigen receptor T cell (CAR-T) therapy associated cytokine release syndrome. Since severe COVID-19 and CAR-T cytokine release syndrome present similarly, it is postulated that selective IL- 6 receptor blockade may attenuate disease severity by modulating hyperinflammation [64]. The RECOVERY trial including hospitalized COVID-19 patients with hypoxia (oxygen saturation $<92 \%$ on air or requiring oxygen therapy) and systemic inflammation (C-reactive protein $\geq 75 \mathrm{mg} / \mathrm{L}$ ) demonstrated a significant decrease in 28-day mortality in those receiving tocilizumab compared to those undergoing standard of care. The benefit of tocilizumab remained in subgroups of patients receiving systemic corticosteroids. Among patients who did not require mechanical ventilation at the beginning, tocilizumab groups were also less likely to have the composite outcome of invasive mechanical ventilation or death [65]. Randomized controlled trials of tocilizumab in COVID-19 have not demonstrated any mortality benefit or clinical improvement in critically ill patients with COVID-19 [66-70]. However, according to the Infectious Disease Society of America (IDSA) COVID guideline, using tocilizumab in addition to steroid is suggested for hospitalized COVID-19 patients with elevated markers of systemic inflammation such as C-reactive protein $\geq 75 \mathrm{mg} / \mathrm{L}$ and severe illness defined as $\mathrm{SpO}_{2} \leq 94 \%$ on room air or supplemental oxygen requirement or critical illness including on mechanical ventilator, extracorporeal membrane oxygenation (ECMO), or sepsis with end-organ dysfunction [71].

\subsubsection{Oral Antiviral Therapies for COVID-19}

Two oral therapies for COVID-19 that have received EUA from the U.S. FDA are nirmatrelvir/ritonavir (Paxlovid) of Pfizer and molnupiravir (Lagevrio) of Merck. Both are used early in disease (within 5 days of symptom onset) for high-risk patients who are at risk for progression to 
hospitalization or death. Given significant drug-drug interaction between ritonavir and CNI, nirmatrelvir/ritonavir is difficult to utilize in most kidney transplant recipients due to the challenge in achieving the goal for therapeutic CNI level. Molnupiravir is likely less effective than a monoclonal antibody with activity against circulating variants or nirmatrelvir/ritonavir. It has not been studied in transplant recipients. Therefore, nirmatrelvir/ritonavir should be considered a second-line drug if more effective alternatives are available. According to the AST, early use of a monoclonal antibody or outpatient intravenous remdesivir is preferable in transplant patients as first-line therapy to prevent the progression of COVID-19 [72].

Proposed algorithm for antiviral therapy in kidney transplant recipients with COVID-19 in early 2022 when the Omicron and Delta variants are the variants of concern (Figure 3).

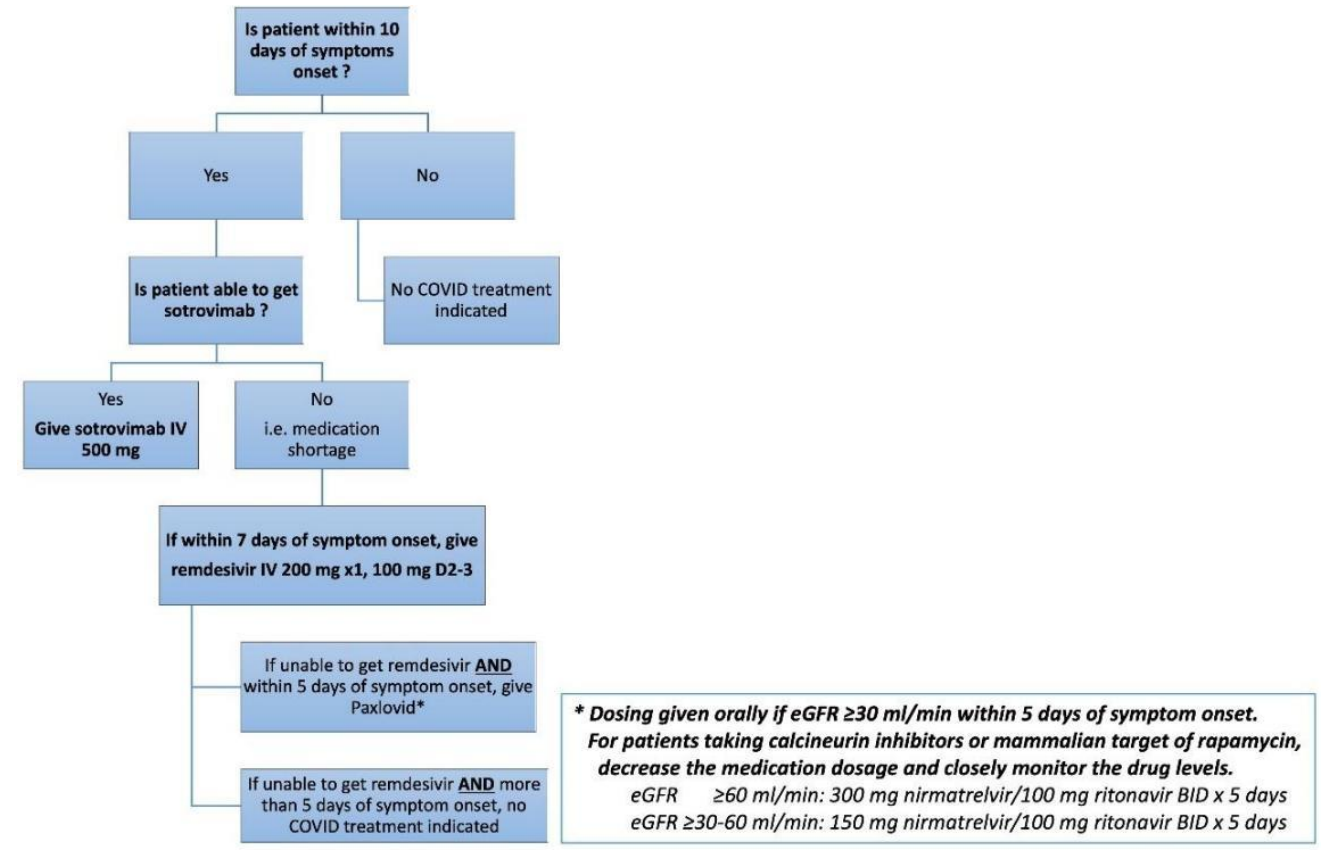

Figure 3 Proposed algorithm for antiviral therapy in kidney transplant recipients with COVID-19 in early 2022.

\subsection{Treatment of COVID-19 Complication}

\subsubsection{Outpatient Management}

The mainstay of COVID-19 treatment is symptomatic treatment with antipyretics, analgesics, cough suppressants, and immunosuppressive medication management. Patient education, patient counseling, and infection control at home are key to outpatient management of COVID-19. Patients should be warned about the symptoms that should prompt evaluation by a health care provider or emergency department visit. These symptoms include worsening dyspnea, mental status changes, severe diarrhea, low blood pressure, and low oxygen saturation level below 90\%. Anti-rejection medications may be reduced as mentioned above in Maintenance immunosuppressive management during the pandemic section.

\subsubsection{Inpatient Management}

The most important step in the inpatient management of COVID-19 is to stabilize the hemodynamics and to secure the airway. For kidney transplant recipients with COVID-19, empiric antibiotics to cover for bacterial pneumonia should be considered due to the immunosuppressed 
status. If azithromycin is used, drug interaction between azithromycin and CNI needs to be monitored. NIH recommends empiric therapy for influenza for patients hospitalized with suspected or documented COVID-19 in locations where the influenza virus is circulating [73]. Antiviral therapy for influenza should be discontinued if molecular testing for influenza is negative from upper respiratory tract specimens in non-intubated patients and both upper and lower respiratory tract specimens in intubated patients [74]. Inhaled medications are preferred to nebulized medications to avoid aerosolization of the viruses. Pharmacologic prophylaxis of venous thromboembolism is recommended for all hospitalized patients with COVID-19. If the patient has evidence of a thromboembolic phenomenon, anticoagulation should be started per the standard of care. In patients with neurological complications such as encephalopathy, Guillain-Barré syndrome, and acute myelitis, the management of such conditions remains the same as non-infected patients [75]. Infection control such as the type of room and personal protective equipment should be strictly implemented according to CDC guidelines.

\subsubsection{Management of AKI}

The consensus report of the $25^{\text {th }}$ Acute Disease Quality Initiative (ADQI) Workgroup recommends strategies to manage COVID-19 associated AKI which is summarized in Table 1 [76].

Table 1 Recommended strategies to manage COVID-19 associated acute kidney injury.

1. Prevention and management of AKI depend on the risk and stage of AKI. Strategies based on Kidney Disease: Improving Global Outcomes (KDIGO) guideline.

2. Individualized fluid and hemodynamic management based on a dynamic assessment of cardiovascular status.

3. Using balanced crystalloids as initial management for expansion of intravascular volume in patients at risk of or with COVID-19 AKI unless an indication for other fluids exists.

4. Monitoring for hyperglycemia and use of intensive glucose-lowering strategies in high-risk patients.

5. Limiting nephrotoxic drug exposure where possible and with careful monitoring when nephrotoxins are required.

6. Optimization of intravascular volume status as the only specific intervention to prevent contrast-induced nephropathy.

Adapted from the consensus report of the $25^{\text {th }}$ Acute Disease Quality Initiative (ADQI) Workgroup [76].

\section{Emerging COVID Vaccine}

Current successful human antiviral vaccination, including influenza and measles vaccines, largely depends on the induction of active immunization to create antibody response. Recent evidence suggests that effective protection against SARS-CoV-2 requires both humoral and cell-mediated immunity [77]. Previous studies demonstrate that the phenotype of T cells induced by vaccination may be important, as less severe cases of SARS showed accelerated induction of T helper cell type 1 (Th1), while T helper cell type 2 (Th2) induction was associated with enhancement of lung disease following infection in patients vaccinated with inactivated SARS-CoV viral vaccine [77]. Therefore, COVID-19 vaccination capable of inducing a skewed Th1 phenotype is of great interest. There are currently 4 major vaccination platforms used in developing COVID-19 vaccines: inactivated virus, protein subunits, non-replicating viral vector, and messenger ribonucleic acid (mRNA) (Table 2). 
Table 2 Summarized previously approved COVID-19 vaccines at the beginning of 2021 categorized by the mechanism to compare and contrast their Th Skew of adjuvant/ vaccine components, efficacy, and distributions

\begin{tabular}{|c|c|c|c|c|}
\hline $\begin{array}{l}\text { Vaccine } \\
\text { Platform }\end{array}$ & Vaccine & $\begin{array}{l}\text { Th Skew of } \\
\text { adjuvant/ vaccine } \\
\text { components }\end{array}$ & Efficacy & Approved Countries \\
\hline $\begin{array}{l}\text { Inactivated } \\
\text { virus }\end{array}$ & Bharat Biotech & Th1 & Pending & 1 Country: India \\
\hline $\begin{array}{l}\text { Protein } \\
\text { subunit }\end{array}$ & EpiVac Corona & Th2 & Pending & 1 country: Russia \\
\hline
\end{tabular}




\begin{tabular}{|c|c|c|c|c|}
\hline & $\begin{array}{l}\text { Johnson and } \\
\text { Johnson [80] }\end{array}$ & No adjuvant & $\begin{array}{l}66 \% \text { in } 44,325 \text { participants } \\
\text { in Argentina, Brazil, Chile, } \\
\text { Colombia, Mexico, Peru, } \\
\text { South Africa, and the US } \\
\text { [80] }\end{array}$ & 3 Countries: Bahrain, South Africa, United States \\
\hline & Cansino & No adjuvant & Pending & 2 Countries: China, Mexico \\
\hline & $\begin{array}{l}\text { Gamaleya [81, } \\
\text { 82] }\end{array}$ & No adjuvant & $\begin{array}{l}91.6 \% \text { in } 19,902 \\
\text { participants in Russia [81, } \\
82]\end{array}$ & $\begin{array}{l}20 \text { Countries: Algeria, Argentina, Belarus, Bolivia, Guinea, } \\
\text { Hungary, Iran, Lebanon, Mongolia, Myanmar, Nicaragua, } \\
\text { Pakistan, Paraguay, Republic of Serbia, Russia, Tunisia, } \\
\text { Turkmenistan, United Arab Emirates, Venezuela, West Bank }\end{array}$ \\
\hline$m R N A$ & Pfizer [83] & $\begin{array}{l}\text { RNA- Th1 skew } \\
\text { Lipid } \\
\text { nanoparticles-Th2 } \\
\text { skew }\end{array}$ & $\begin{array}{l}95 \% \text { in } 43,548 \text { participants } \\
\text { in Argentina, Brazil, } \\
\text { Germany, South Africa, } \\
\text { Turkey, USA [83] }\end{array}$ & $\begin{array}{l}57 \text { countries: } \\
\text { Argentina, Australia, Austria, Bahrain, Belgium, Bulgaria, } \\
\text { Canada, Chile, Colombia, Costa Rica, Croatia, Cyprus, Czech } \\
\text { Republic, Denmark, Ecuador, Estonia, Finland, France, Germany, } \\
\text { Greece, Hong Kong, Hungary, Iceland, Iraq, Ireland, Israel, Italy, } \\
\text { Jordan, Kuwait, Latvia, Liechtenstein, Lithuania, Luxembourg, } \\
\text { Malta, Mexico, Mongolia, Netherlands, New, Zealand, Norway, } \\
\text { Oman, Panama, Philippines, Poland, Portugal, Qatar, Republic of } \\
\text { Serbia, Romania, Saudi Arabia, Singapore, Slovakia, Slovenia, } \\
\text { Spain, Sweden, Switzerland, United Arab Emirates, United } \\
\text { Kingdom, United States }\end{array}$ \\
\hline
\end{tabular}




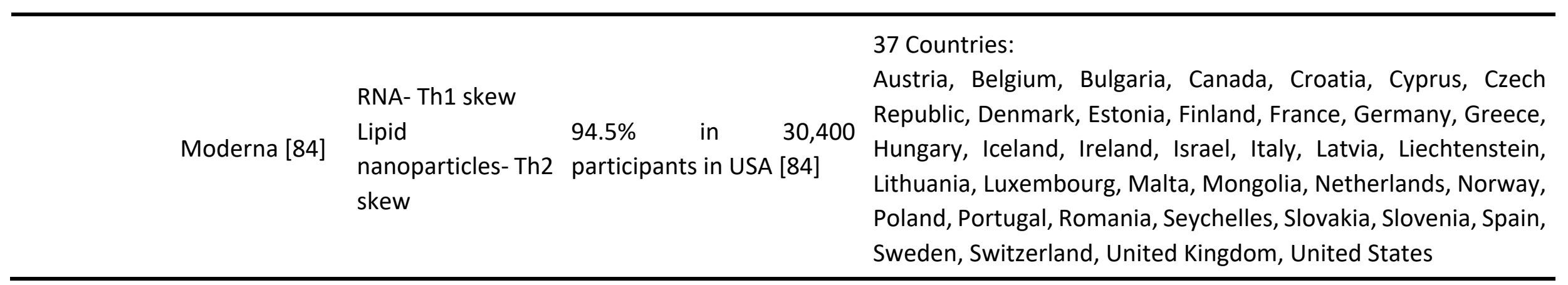

Th1, Thelper cell type 1; Th2, Thelper cell type 2 


\subsection{Vaccine Allocation and Accessibility}

At the end of 2020 when COVID-19 vaccines were introduced to start using clinically and there were some countries in which the leading COVID-19 vaccines were approved (Table 2). Since the number of people in need of vaccination greatly exceeded the number of vaccines available, state and federal governments took recommendations from the CDC to create a priority list based on the risk of developing severe complications from COVID-19. Kidney transplant recipients were considered high-risk health conditions and were therefore included in Group $1 \mathrm{~b}$ or Group 1c depending on the age criteria (Figure 4). Since there is more available vaccine supply, clinical studies, and extension of eligibility criteria including for children and teenagers, vaccine allocation has been continuously updated to prevent serious outcomes of COVID-19 including severe disease, hospitalization, and death [85].
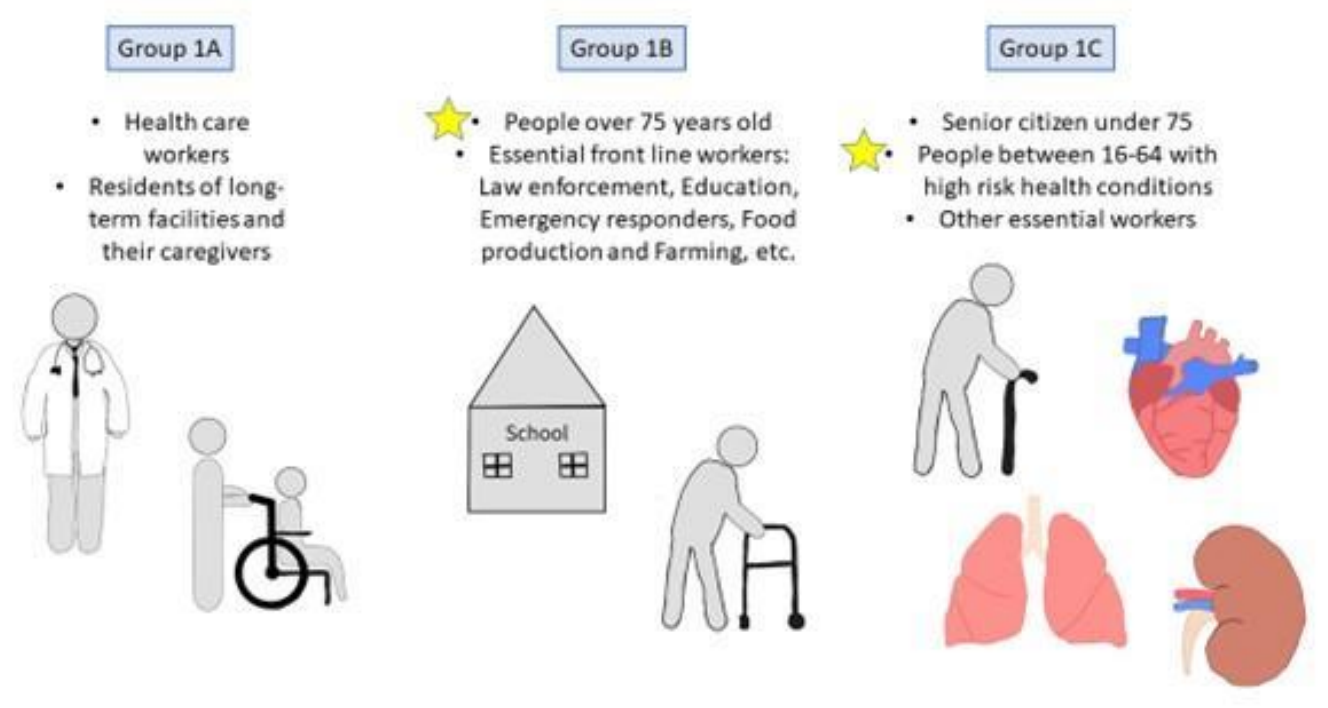

Figure 4 Category in the order of priority access to COVID19 vaccine at the beginning of vaccine availability in early 2021.

\subsection{Vaccination of Kidney Transplant Recipients (KTR)}

Currently, no clinical trials have reported on the safety and efficacy of COVID-19 vaccination in KTR. In terms of safety, most vaccines besides the live attenuated vaccine are thought to be safe in KTR [86]. A systematic review and meta-analysis revealed that vaccination was not significantly associated with an increased risk of rejection compared to no vaccination in solid organ transplantation [87].

A major concern for vaccination in KTR is the effectiveness of the vaccine given the immunosuppressive medications may suppress the mechanism to generate immunity against SARSCoV-2. In KTR, the T cells are being persistently suppressed from rATG induction and maintenance immunosuppressive medications. Immunosuppressive medications, particularly, rATG have been shown to cause a long-term decrease in Th1, but not Th2 response in KTR [88]. Several studies demonstrated seroprotection among the majority of influenza-vaccinated KTR, and this evidence suggests a strong Th2 response [89]. Therefore, choosing a vaccination platform that has a Th1 
skewed response may deem beneficial for KTR to protect against COVID-19. Theoretical mechanism of immune response in the immunosuppressed state among kidney transplant recipients and vaccine characteristics may be taken into consideration while further studies may guide appropriate types of vaccine.

For newly transplanted patients, we typically wait for 3-4 months after the surgery to give inactivated vaccines. KTR are eligible and prioritized to get COVID vaccines due to their high risk of developing severe COVID-19. The AST recommends giving COVID vaccine earlier at 1 month after transplant surgery or ideally at least 2 weeks before transplant surgery [90]. The patients may have reactions to the COVID vaccine similar to non-transplant patients. In the study of immunogenicity of the first dose of the mRNA SARS-CoV-2 vaccine among solid organ transplant recipients, the majority of participants did not mount appreciable anti-spike antibody responses [91]. However, a study including kidney or kidney-pancreas transplant recipients previously having the first dose of mRNA-1273 (Moderna) vaccine and then receiving the second dose revealed that $65 \%$ of patients with SARS-CoV-2-naïve (no signs of either cellular or humoral response determined by negative IgM/IgG spike (S) antibodies and ELISpot against the nucleocapsid (N) and the S protein at 2 weeks before receiving the second dose of vaccine) developed either humoral or cellular response. Diabetes and antithymocyte globulin therapy during the last year were associated with vaccine unresponsiveness [92]. KTR may remain at higher early risk for COVID-19 despite vaccination.

Effectiveness of 2-doses of mRNA COVID-19 vaccination against COVID-19-associated hospitalizations is lower among immunocompromised compared to immunocompetent adults (70\% vs $90 \%$ ) [93]. Although some transplant recipients develop new and/or increased humoral and cellular immune responses to the $3^{\text {rd }}$ dose of mRNA COVID-19 vaccine [94-97], 67\% of patients with negative titers after the $2^{\text {nd }}$ dose continue to have negative titers after the $3^{\text {rd }}$ dose and up to $32 \%$ of patients still had undetectable antibody titers 4 weeks after the third dose [94, 95]. According to the $C D C$, immunocompromised adults including transplant recipients should receive primary series of mRNA COVID-19 vaccine 2 doses (21 and 28 days apart for Pfizer-BioNTech and Moderna, respectively) and an additional primary shot ( $3^{\text {rd }}$ dose) 28 days after the $2^{\text {nd }}$ dose. In addition, they should receive a booster shot of mRNA COVID-19 vaccine ( $4^{\text {th }}$ dose) 5 months after the additional primary shot [98] to protect against COVID-19 in the face of the Omicron variant, which currently causes an increase in COVID-19 cases. In addition to vaccination, standard COVID precautions such as wearing masks, hand sanitization, and social distancing should be continued in KTR despite receipt of the COVID vaccines. In addition, close contact persons including household members should also receive COVID-19 vaccines to protect kidney transplant recipients from COVID-19 infection [99].

As of January 14, 2022, three vaccines are authorized and approved for use in the United States to prevent COVID-19. Pfizer-BioNTech or Moderna (COVID-19 mRNA vaccines) are preferred for transplant patients due to the higher likelihood of developing antibody response. Different types of COVID vaccines have different mechanisms and require the different number of shots (Table 3) [85, 99].

Table 3 Timeline for primary series COVID-19 vaccination and a booster shot in kidney transplant recipients.

\begin{tabular}{llll}
\hline $\begin{array}{l}\text { Sequence of } \\
\text { COVID-19 vaccination }\end{array}$ & Pfizer-BioNTech & Moderna & $\begin{array}{l}\text { Johnson } \\
\text { Johnson's Janssen }\end{array}$ \\
\hline
\end{tabular}




\begin{tabular}{|c|c|c|c|}
\hline \multicolumn{4}{|c|}{ Primary series for kidney transplant recipients } \\
\hline $2^{\text {nd }}$ shot & $\begin{array}{l}\text { Given } 21 \text { days after } \\
\text { the } 1 \text { st shot }\end{array}$ & $\begin{array}{l}\text { Given } 28 \text { days after } \\
\text { the } 1 \text { st shot }\end{array}$ & Not applicable \\
\hline $\begin{array}{l}\text { Additional primary shot } \\
\text { ( } 3^{\text {rd }} \text { shot) }\end{array}$ & $\begin{array}{l}\text { Given } 28 \text { days after } \\
\text { the } 2^{\text {nd }} \text { shot }\end{array}$ & $\begin{array}{l}\text { Given } 28 \text { days after } \\
\text { the } 2^{\text {nd }} \text { shot }\end{array}$ & $\begin{array}{l}\text { No additional } \\
\text { primary shot is } \\
\text { recommended at } \\
\text { this time }\end{array}$ \\
\hline $\begin{array}{l}\text { Total number of the } \\
\text { shots for primary series } \\
\text { A Booster Shot }\end{array}$ & $3 *$ & $3^{*}$ & 1 \\
\hline A booster ( $4^{\text {th }}$ shot) & $\begin{array}{l}\text { Given } 5 \text { months after } \\
\text { the additional } \\
\text { primary shot }\end{array}$ & $\begin{array}{l}\text { Given } 5 \text { months } \\
\text { after the additional } \\
\text { primary shot }\end{array}$ & $\begin{array}{l}\text { Given } 2 \text { months after } \\
\text { the } 1^{\text {st }} \text { shot }\end{array}$ \\
\hline
\end{tabular}

*When scheduling the additional primary shot ( $3^{\text {rd }}$ shot), kidney transplant patients will need to notify the pharmacists or health care providers that they are transplant patients on immunosuppressive drugs and require the $3^{\text {rd }}$ shot to complete primary series of COVID vaccination.

For kidney transplant recipients who tested positive for COVID-19, the vaccine should still be given; however, the ideal period for vaccination after infection remains unknown. However, the patients should wait until all symptoms are resolved and the isolation period has ended [85, 99]. If the patients had received monoclonal antibodies for the treatment of COVID-19, vaccination should be given 90 days after the completion of monoclonal antibody treatment [85].

Reduced effectiveness of the mRNA COVID-19 vaccines in kidney transplant recipients has brought up the need for other ways to prevent COVID-19 infection and severity in this population. The most recent long-acting antibody combination, Evusheld (tixagevimab co-packaged with cilgavimab; formerly AZD7442), has received EUA in the United States for the pre-exposure prophylaxis of COVID-19. A phase III multi-center randomized, double-blind, placebo-controlled trial (PROVENT) investigates the safety and efficacy of Evusheld for pre-exposure prophylaxis of COVID19 in 5,197 unvaccinated adults randomized into Evusheld or placebo in a 2:1 ratio. There are 196 immunocompromised participants. After following up the study participants an average of 83 days and having a total of 25 cases, the trial met its primary efficacy endpoint with a $77 \%$ reduction in symptomatic COVID-19 among those who received Evusheld compared with those receiving placebo up to 183 days. There was no difference in rates of adverse events between both groups. Evusheld may be an add-on preventive strategy for COVID-19 in kidney transplant recipients, whose response rate to mRNA COVID-19 vaccine is lower than the general population, and in those recipients for whom COVID-19 vaccination is not recommended [100]. However, effectiveness and adverse drug reactions from a long-term follow-up are required. Data from another phase III doubleblind, placebo-controlled trial of AZD7442 for post-exposure prophylaxis of COVID-19 in Adults (STORM CHASER; NCT04625972) is ongoing and the result of this trial may change some practice of transplantation during the COVID-19 pandemic [101]. Although the result of the efficacy of prophylactic monoclonal antibody is promising, it should not substitute for vaccination or other primary preventive strategies including masking, social distancing, and avoidance of large indoor social gatherings [102]. 


\section{Conclusion}

It has been challenging from the beginning of the COVID-19 pandemic at the end of 2019 until the current time in early 2022. The pandemic has impacted all countries worldwide including kidney transplantation and the care of the kidney transplant recipients. Living donor kidney transplantations decreased since the COVID-19 pandemic and although the number of living donor kidney transplantations slightly increased in the subsequent year, further attention and strategies are needed to increase living kidney donation with safety policies and practices for donors, recipients, and transplant providers. Kidney transplant recipients are at high risk of developing severe complications from COVID-19 due to underlying comorbidities and immunosuppressed status. The immunosuppressive management including the induction therapy and maintenance immunosuppressive regimen have been modified at many transplant centers. In SARS-CoV-2 infected kidney transplant recipients, the immunosuppression is usually reduced. In patients who do not have active COVID-19, the acute rejection treatment is usually individualized based on the risk and benefit. The effectiveness of vaccination against the SARS-COV-2 virus in kidney transplant recipients is lower compared to general population and pre- and post-exposure prophylaxis with a long-acting monoclonal antibody may be promising adjunct to the COVID-19 vaccination. Drug-drug interactions between new oral anti-COVID-19 medications and CNI as well as the efficacy of these oral antiviral therapies remain challenging. Further studies are necessary to establish standard guidelines for immunosuppressive management in kidney transplant recipients who were diagnosed with COVID-19 and to better understand the outcome of the vaccine and anti-COVID-19 prophylaxis and therapies in this high-risk population.

\section{Abbreviations}

ACE2, angiotensin-converting enzyme 2

ADQI, Acute Disease Quality Initiative

AKI, acute kidney injury

Ang II, angiotensin-II

ARDS, severe acute respiratory distress syndrome

AST, American society of transplantation

AT1R, angiotensin II type 1 receptor

CKD, chronic kidney disease

CMS, Centers for Medicare and Medicaid Services

$\mathrm{CNI}$, calcineurin inhibitor

COVAN, coronavirus-associated nephropathy

COVID-19, novel coronavirus disease 2019

ECMO, extracorporeal membrane oxygenation

eGFR, estimated glomerular filtration rate

EUA, emergency use authorization

FDA, Food and Drug Administration

IDSA, Infectious Disease Society of America

mRNA, messenger ribonucleic acid

mTOR, mammalian target of rapamycin

OPTN, Organ Procurement and Transplantation Network

KDIGO, Kidney Disease: Improving Global Outcomes

$K R T$, kidney replacement therapy

NAAT, nucleic acid amplification test

$\mathrm{NIH}$, National Institutes of Health 
RD-Ad, replication-deficient adenovirus

rATG, rabbit antithymocyte globulin

RECOVERY, Randomised Evaluation of COVID-19 Therapy

SARS-CoV-2, severe acute respiratory virus syndrome coronavirus 2

TANGO, Post-Transplant Glomerular Diseases

Th1, T helper cell type 1

Th2, T helper cell type 2

UNOS, United Network for Organ Sharing

U.S., United States

\section{Acknowledgment}

Authors appreciate our patients for the knowledge and experience we gain from clinical care and research.

\section{Author Contributions}

A.J., N.E., and E.T. designed the overall reviewed topics of the manuscript, wrote the first draft of the manuscript, created tables and figures, and revised the manuscript. L.H. wrote the first draft of the manuscript, revised the manuscript, and provided kidney pathology pictures. N.T., M.T., P.G., K.Z., Y.C., H.Y., R.C.F., and B.P.C. wrote the first draft of the manuscript and revised the manuscript.

\section{Competing Interests}

Authors have nothing to declare.

\section{References}

1. World Health Organization. Timeline: WHO's COVID-19 response [Internet]. Geneva, Switzerland: World Health Organization; 2021 [cited date 2021 April 25]. Available from: https://www.who.int/emergencies/diseases/novel-coronavirus-2019/interactive-timeline.

2. World Health Organization. Coronavirus disease (COVID-19) pandemic. Last update: January 14, 2022, 09:03 AM GMT-8 [Internet]. Geneva, Switzerland: World Health Organization; 2022 [cited date 2022 January 16]. Available from: https://www.who.int/emergencies/diseases/novelcoronavirus-2019.

3. Centers for Disease Control and Prevention. COVID-19 data tracker. United States COVID-19 cases, deaths, and laboratory testing (NAATs) by State, territory, and jurisdiction. Data as of: January 15, 2022 4:53 PM ET [Internet]. Atlanta, Georgia, U.S.: Centers for Disease Control and Prevention; 2022 [cited date 2022 January 16]. Available from: https://covid.cdc.gov/coviddata-tracker/\#cases totalcases.

4. Centers for Disease Control and Prevention. COVID-19. What you need to know about variants [Internet]. Atlanta, Georgia, U.S.: Centers for Disease Control and Prevention; 2021. Available from: https://www.cdc.gov/coronavirus/2019-ncov/variants/aboutvariants.html?CDC AA refVal=https\%3A\%2F\%2Fwww.cdc.gov\%2Fcoronavirus\%2F2019ncov\%2Fvariants\%2Fvariant.html.

5. Loupy A, Aubert O, Reese PP, Bastien O, Bayer F, Jacquelinet C. Organ procurement and transplantation during the COVID-19 pandemic. Lancet. 2020; 395: E95-E96. 
6. Organ Procurement and Transplantation Network. National data. U.S. Department of Health \& Human Services, 2022 [cited date 2022 January 16]. Available from: https://optn.transplant.hrsa.gov/data/view-data-reports/national-data/.

7. Craig-Schapiro R, Salinas T, Lubetzky M, Abel BT, Sultan S, Lee JR, et al. COVID-19 outcomes in patients waitlisted for kidney transplantation and kidney transplant recipients. Am J Transplant. 2021; 21: 1576-1585.

8. Tantisattamo E, Ferrey AJ, Reddy UG, Ichii H, Dafoe DC, Kalantar-Zadeh K. Haddon matrix for kidney transplantation during COVID-19 pandemic: A problem solving framework for present and future. Transpl Infect Dis. 2020; 22: e13373.

9. American Society of Transplantation. COVID-19 (coronavirus): FAQs for organ transplantation [Internet]. NJ, USA: American Society of Transplantation; 2021 [cited date 2022 January 15]. Available from:

https://www.myast.org/sites/default/files/2021\%200809\%20COVID19\%20FAQ.pdf.

10. Centers for Medicare \& Medicaid Services. Non-emergent, elective medical services, and treatment recommendations [Internet]. Baltimore County, Maryland: Centers for Medicare \& Medicaid Services; 2020 [cited date 2021 April 25]. Available from:

https://www.cms.gov/files/document/cms-non-emergent-elective-medicalrecommendations.pdf.

11. Imam A, Abukhalaf SA, Imam R, Abu-Gazala S, Merhav H, Khalaileh A. Kidney transplantation in the times of covid-19 - a literature review. Ann Transplant. 2020; 25: e925755-1-e925755-16.

12. Pereira MR, Mohan S, Cohen DJ, Husain SA, Dube GK, Ratner LE, et al. COVID-19 in solid organ transplant recipients: Initial report from the US epicenter. Am J Transplant. 2020; 20: 18001808.

13. Akalin E, Azzi Y, Bartash R, Seethamraju H, Parides M, Hemmige V, et al. Covid-19 and kidney transplantation. N Engl J Med. 2020; 382: 2475-2477.

14. Husain SA, Dube G, Morris H, Fernandez H, Chang JH, Paget K, et al. Early outcomes of outpatient management of kidney transplant recipients with coronavirus disease 2019. Clin J Am Soc Nephrol. 2020; 15: 1174-1178.

15. Banerjee D, Popoola J, Shah S, Ster IC, Quan V, Phanish M. COVID-19 infection in kidney transplant recipients. Kidney Int. 2020; 97: 1076-1082.

16. Gandolfini I, Delsante M, Fiaccadori E, Zaza G, Manenti L, Degli Antoni A, et al. COVID-19 in kidney transplant recipients. Am J Transplant. 2020; 20: 1941-1943.

17. Infectious Diseases Society of America. Solid organ transplant \& immunosuppressive medications 2020 [Internet]. Arlington, Virginia: Infectious Diseases Society of America; 2020. Available from: https://www.idsociety.org/covid-19-real-time-learning-network/specialpopulations/solid-organ-transplant--immunosuppressive-medications/\#treatment.

18. Nair V, Jandovitz N, Hirsch JS, Nair G, Abate M, Bhaskaran M, et al. COVID-19 in kidney transplant recipients. Am J Transplant. 2020; 20: 1819-1825.

19. Conti P, Ronconi G, Caraffa A, Gallenga CE, Ross R, Frydas I, et al. Induction of pro-inflammatory cytokines (IL-1 and IL-6) and lung inflammation by Coronavirus-19 (COVI-19 or SARS-CoV-2): Anti-inflammatory strategies. J Biol Regul Homeost Agents. 2020; 34: 327-331.

20. Alhamad T, Lubetzky M, Lentine KL, Edusei E, Parsons R, Pavlakis $M$, et al. Kidney recipients with allograft failure, transition of kidney care (KRAFT): A survey of contemporary practices of transplant providers. Am J Transplant. 2021; 21: 3034-3042.

21. Tantisattamo E, Dafoe DC, Ferrey AJ, Ichii H, Lee RA, Zuckerman JE, et al. Kidney allograft infarction associated with transplant renal artery stenosis in a COVID-19 kidney transplant recipient. Clin Nephrol Case Stud. 2021; 9: 93-104. 
22. Bowe B, Cai M, Xie Y, Gibson AK, Maddukuri G, Al-Aly Z. Acute kidney injury in a national cohort of hospitalized US veterans with COVID-19. Clin J Am Soc Nephrol. 2021; 16: 14-25.

23. Cheng $Y$, Luo $R$, Wang $X$, Wang $K$, Zhang $N$, Zhang $M$, et al. The incidence, risk factors, and prognosis of acute kidney injury in adult patients with Coronavirus Disease 2019. Clin J Am Soc Nephrol. 2020; 15: 1394-1402.

24. Robbins-Juarez SY, Qian L, King KL, Stevens JS, Husain SA, Radhakrishnan J, et al. Outcomes for patients with COVID-19 and acute kidney injury: A systematic review and meta-analysis. Kidney Int Rep. 2020; 5: 1149-1160.

25. Gupta S, Coca SG, Chan L, Melamed ML, Brenner SK, Hayek SS, et al. AKI treated with renal replacement therapy in critically III patients with COVID-19. J Am Soc Nephrol. 2021; 32: 161176.

26. Cravedi P, Mothi SS, Azzi Y, Haverly M, Farouk SS, Pérez-Sáez MJ, et al. COVID-19 and kidney transplantation: Results from the TANGO International Transplant Consortium. Am J Transplant. 2020; 20: 3140-3148.

27. Kudose S, Batal I, Santoriello D, Xu K, Barasch J, Peleg Y, et al. Kidney biopsy findings in patients with COVID-19. J Am Soc Nephrol. 2020; 31: 1959-1968.

28. Ammous A, Ghaffar MA, El-Charabaty E, El-Sayegh S. Renal infarction in COVID-19 patient. J Nephrol. 2021; 34: 267-268.

29. Post A, den Deurwaarder ES, Bakker SJ, de Haas RJ, van Meurs M, Gansevoort RT, et al. Kidney infarction in patients with COVID-19. Am J Kidney Dis. 2020; 76: 431-435.

30. Webb C, Jones ES, Wearne N, Chetty DR, Blom D, Barday Z, et al. COVID-19 associated graft loss from renal infarction in a kidney transplant recipient. Kidney Int Rep. 2021; 6: 1166-1169.

31. Bernard I, Limonta D, Mahal LK, Hobman TC. Endothelium infection and dysregulation by SARSCoV-2: Evidence and caveats in COVID-19. Viruses. 2020; 13: 29.

32. Zhang $S$, Liu $Y$, Wang $X$, Yang L, Li H, Wang $Y$, et al. SARS-CoV-2 binds platelet ACE2 to enhance thrombosis in COVID-19. J Hematol Oncol. 2020; 13: 1-22.

33. Zheng KI, Feng G, Liu WY, Targher G, Byrne CD, Zheng MH. Extrapulmonary complications of COVID-19: A multisystem disease? J Med Virol. 2021; 93: 323-335.

34. Aziz H, Lashkari N, Yoon YC, Kim J, Sher LS, Genyk Y, et al. Effects of Coronavirus Disease 2019 on solid organ transplantation. Transplant Proc. 2020; 52: 2642-2653.

35. Nakajima Y, Ogai A, Furukawa K, Arai R, Anan R, Nakano Y, et al. Prolonged viral shedding of SARS-CoV-2 in an immunocompromised patient. J Infect Chemother. 2021; 27: 387-389.

36. Russell CD, Millar JE, Baillie JK. Clinical evidence does not support corticosteroid treatment for 2019-nCoV lung injury. Lancet. 2020; 395: 473-475.

37. Edalatifard M, Akhtari M, Salehi M, Naderi Z, Jamshidi A, Mostafaei S, et al. Intravenous methylprednisolone pulse as a treatment for hospitalised severe COVID-19 patients: Results from a randomised controlled clinical trial. Eur Respir J. 2020; 56: 2002808.

38. Sterne JA, Murthy S, Diaz JV, Slutsky AS, Villar J, Angus DC, et al. Association between administration of systemic corticosteroids and mortality among critically III patients with COVID-19: A meta-analysis. JAMA. 2020; 324: 1330-1341.

39. RECOVERY Collaborative Group. Dexamethasone in hospitalized patients with Covid-19. N Engl J Med. 2021; 384: 693-704.

40. U.S. Food and Drug Administration. Coronavirus (COVID-19) update: FDA revokes emergency use authorization for chloroquine and hydroxychloroquine [Internet]. Silver Spring, Maryland: U.S. Food and Drug Administration; 2020 [cited date 2021 April 25]. Available from: https://www.fda.gov/news-events/press-announcements/coronavirus-covid-19-update-fdarevokes-emergency-use-authorization-chloroquine-and. 
41. Thakare S, Gandhi C, Modi T, Bose S, Deb S, Saxena N, et al. Safety of remdesivir in patients with acute kidney injury or CKD. Kidney Int Rep. 2021; 6: 206-210.

42. Beigel JH, Tomashek KM, Dodd LE, Mehta AK, Zingman BS, Kalil AC, et al. Remdesivir for the treatment of Covid-19 - final report. N Engl J Med. 2020; 383: 1813-1826.

43. WHO Solidarity Trial Consortium. Repurposed antiviral drugs for Covid-19 - Interim WHO solidarity trial results. N Engl J Med. 2021; 384: 497-511.

44. Remdesivir (Veklury ${ }^{\circledR}$ ) [package insert]. Food and Drug Administration; 2020 [cited date 2022 January 26]. Available from:

https://www.accessdata.fda.gov/drugsatfda docs/label/2020/2147870rig1s000lbl.pdf.

45. Ackley TW, McManus D, Topal JE, Cicali B, Shah S. A valid warning or clinical lore: An evaluation of safety outcomes of remdesivir in patients with impaired renal function from a multicenter matched cohort. Antimicrob Agents Chemother. 2021; 65. doi: 10.1128/AAC.02290-20.

46. Buxeda A, Arias-Cabrales C, Perez-Saez MJ, Cacho J, Cabello Pelegrin S, Melilli E, et al. Use and safety of remdesivir in kidney transplant recipients with COVID-19. Kidney Int Rep. 2021; 6: 2305-2315.

47. Shafiekhani M, Shahabinezhad F, Niknam T, Tara SA, Haem E, Mardani P, et al. Evaluation of the therapeutic regimen in COVID-19 in transplant patients: Where do immunomodulatory and antivirals stand? Virol J. 2021; 18: 1-10.

48. Joyner MJ, Carter RE, Senefeld JW, Klassen SA, Mills JR, Johnson PW, et al. Convalescent plasma antibody levels and the risk of death from Covid-19. N Engl J Med. 2021; 384: 1015-1027.

49. Rojas M, Rodriguez Y, Monsalve DM, Acosta-Ampudia Y, Camacho B, Gallo JE, et al. Convalescent plasma in Covid-19: Possible mechanisms of action. Autoimmun Rev. 2020; 19: 102554.

50. Rahman F, Liu ST, Taimur S, Jacobs S, Sullivan T, Dunn D, et al. Treatment with convalescent plasma in solid organ transplant recipients with COVID-19: Experience at large transplant center in New York City. Clin Transplant. 2020; 34: e14089.

51. Fung M, Nambiar A, Pandey S, Aldrich JM, Teraoka J, Freise C, et al. Treatment of immunocompromised COVID-19 patients with convalescent plasma. Transpl Infect Dis. 2021; 23: e13477.

52. National Institutes of Health. COVID-19 treatment guidelines. What's new in the guidelines [Internet]. Bethesda, Maryland: National Institutes of Health; 2022 [cited date 2022 January 15]. Available from: https://www.covid19treatmentguidelines.nih.gov/about-theguidelines/whats-new/.

53. Marston HD, Paules $\mathrm{Cl}$, Fauci AS. Monoclonal antibodies for emerging infectious diseases borrowing from history. N Engl J Med. 2018; 378: 1469-1472.

54. Kumar RN, Wu EL, Stosor V, Moore WJ, Achenbach C, Ison MG, et al. Real-world experience of Bamlanivimab for Coronavirus Disease 2019 (COVID-19): A case-control study. Clin Infect Dis. 2022; 74: 24-31.

55. Jenks JD, Aslam S, Horton LE, Law N, Bharti A, Logan C, et al. Early monoclonal antibody administration can reduce both hospitalizations and mortality in high-risk outpatients with COVID-19. Clin Infect Dis. 2021. doi: 10.1093/cid/ciab522.

56. Weinreich DM, Sivapalasingam S, Norton T, Ali S, Gao H, Bhore R, et al. REGN-COV2, a neutralizing antibody cocktail, in outpatients with Covid-19. N Engl J Med. 2021; 384: 238-251.

57. U.S. Food and Drug Administration. Coronavirus (COVID-19) update: FDA authorizes monoclonal antibody for treatment of COVID-19 2020 [Internet]. Silver Spring, Maryland: U.S. Food and Drug Administration; 2020 [cited date 2021 April 06]. Available from: https://www.fda.gov/news-events/press-announcements/coronavirus-covid-19-update-fdaauthorizes-monoclonal-antibody-treatment-covid-19. 
58. Chen P, Nirula A, Heller B, Gottlieb RL, Boscia J, Morris J, et al. SARS-CoV-2 neutralizing antibody LY-CoV555 in outpatients with Covid-19. N Engl J Med. 2021; 384: 229-237.

59. Yetmar ZA, Beam E, O'Horo JC, Ganesh R, Bierle DM, Brumble L, et al. Monoclonal antibody therapy for COVID-19 in solid organ transplant recipients. Open Forum Infect Dis. 2021; 8: ofab255.

60. Dhand A, Lobo SA, Wolfe K, Feola N, Lee L, Nog R, et al. Casirivimab-imdevimab for treatment of COVID-19 in solid organ transplant recipients: An early experience. Transplantation. 2021; 105: e68-e69.

61. Kutzler HL, Kuzaro HA, Serrano OK, Feingold A, Morgan G, Cheema F. Initial experience of bamlanivimab monotherapy use in solid organ transplant recipients. Transpl Infect Dis. 2021; 23: e13662.

62. U.S. Food and Drug Administration. Fact sheet for healthcare providers emergency use authorization (EUA) of sotrovimab [Internet]. Silver Spring, Maryland: U.S. Food and Drug Administration; 2021 [cited date 2022 January 16]. Available from: https://www.fda.gov/media/149534/download.

63. Cathcart AL, Havenar-Daughton C, Lempp FA, Ma D, Schmid MA, Agostini ML, et al. The dual function monoclonal antibodies VIR-7831 and VIR-7832 demonstrate potent in vitro and in vivo activity against SARS-CoV-2. bioRxiv. 2021. doi: 10.1101/2021.03.09.434607.

64. Mehta P, McAuley DF, Brown M, Sanchez E, Tattersall RS, Manson JJ, et al. COVID-19: Consider cytokine storm syndromes and immunosuppression. Lancet. 2020; 395: 1033-1034.

65. RECOVERY Collaborative Group, Chalmers J, Abo-Leyah H, Loftus $\mathrm{H}$, Spears M. Tocilizumab in patients admitted to hospital with COVID-19 (RECOVERY): A randomised, controlled, openlabel, platform trial. Lancet. 2021; 397: 1637-1645.

66. Stone JH, Frigault MJ, Serling-Boyd NJ, Fernandes AD, Harvey L, Foulkes AS, et al. Efficacy of tocilizumab in patients hospitalized with Covid-19. N Engl J Med. 2020; 383: 2333-2344.

67. Salvarani C, Dolci G, Massari M, Merlo DF, Cavuto S, Savoldi L, et al. Effect of tocilizumab vs standard care on clinical worsening in patients hospitalized with COVID-19 Pneumonia: A randomized clinical trial. JAMA Intern Med. 2021; 181: 24-31.

68. Roche. Roche's phase III EMPACTA study showed Actemra/RoActemra reduced the likelihood of needing mechanical ventilation in hospitalised patients with COVID-19 associated pneumonia 2020 [Internet]. Basel, Switzerland: Roche; 2020 [cited date 2021 April 26]. Available from: https://www.roche.com/dam/icr:2ca93ba2-739c-4b69-a9712a94fca2d818/en/18092020-mr-empacta.pdf.

69. Roche. Roche provides an update on the phase III COVACTA trial of Actemra/RoActemra in hospitalised patients with severe COVID-19 associated pneumonia 2020 [Internet]. Basel, Switzerland: Roche; 2020 [cited date 2021 April 26]. Available from:

https://www.roche.com/dam/jcr:6d8de90d-2e31-43c8-b4e1-0a24a2675015/en/29072020mr-covacta.pdf.

70. Hermine O, Mariette X, Tharaux PL, Resche-Rigon M, Porcher R, Ravaud P, et al. Effect of tocilizumab vs usual care in adults hospitalized with COVID-19 and moderate or severe pneumonia: A randomized clinical trial. JAMA Intern Med. 2021; 181: 32-40.

71. Bhimraj A, Morgan RL, Shumaker AH, Lavergne V, Baden L, Cheng VC, et al. Infectious diseases society of America guidelines on the treatment and management of patients with COVID-19. Clin Infect Dis. 2020. doi: 10.1093/cid/ciaa478.

72. American Society of Transplantation. AST statement on oral antiviral therapy for COVID-19 for organ transplant recipients [Internet]. NJ, USA: American Society of Transplantation; [cited date 2022 January 16]. Available from: 
https://www.myast.org/sites/default/files/AST\%20Statement\%20on\%200ral\%20Antiviral\%20 Therapy\%20for\%20COVID\%20Jan\%204\%20\%282\%29.pdf.

73. National Institutes of Health. COVID-19 treatment guidelines 2021 [Internet]. Bethesda, Maryland: National Institutes of Health; 2021 [cited date 2021 April 26]. Available from: https://www.covid19treatmentguidelines.nih.gov/whats-new/.

74. Kim AY, Gandhi RT. COVID-19: Management in hospitalized adults [Internet]. Waltham: UpToDate; 2021 [cited date 2021 April 26]. Available from: https://www.uptodate.com/contents/covid-19-management-in-hospitalized-adults.

75. Elkind MS, Cucchiara BL, Koralnik IJ. COVID-19: Neurologic complications and management of neurologic conditions [Internet]. Waltham: UpToDate; 2021 [cited date 2021 April 26]. Available from: https://www.uptodate.com/contents/covid-19-neurologic-complicationsand-management-of-neurologic-conditions.

76. Nadim MK, Forni LG, Mehta RL, Connor Jr MJ, Liu KD, Ostermann M, et al. COVID-19-associated acute kidney injury: Consensus report of the 25th Acute Disease Quality Initiative (ADQI) workgroup. Nat Rev Nephrol. 2020; 16: 747-764.

77. Jeyanathan M, Afkhami S, Smaill F, Miller MS, Lichty BD, Xing Z. Immunological considerations for COVID-19 vaccine strategies. Nat Rev Immunol. 2020; 20: 615-632.

78. Lee G, Mak E. China's CNBG/Sinopharm COVID-19 vaccine is $79 \%$ effective [Internet]. Boston, MA: BioWorld; 2020 [cited date 2021 April 26]. Available from:

https://www.bioworld.com/articles/501906-chinas-cnbgsinopharm-covid-19-vaccine-is-79effective.

79. Voysey M, Clemens SA, Madhi SA, Weckx LY, Folegatti PM, Aley PK, et al. Safety and efficacy of the ChAdOx1 nCoV-19 vaccine (AZD1222) against SARS-CoV-2: An interim analysis of four randomised controlled trials in Brazil, South Africa, and the UK. Lancet. 2021; 397: 99-111.

80. National Institutes of Health. Janssen investigational COVID-19 vaccine: Interim analysis of phase 3 clinical data released [Internet]. Bethesda, Maryland: National Institutes of Health; 2021 [cited date 2021 April 26]. Available from: https://www.nih.gov/news-events/newsreleases/janssen-investigational-covid-19-vaccine-interim-analysis-phase-3-clinical-datareleased.

81. Mahase E. Covid-19: Russian vaccine efficacy is $91.6 \%$, show phase III trial results. BMJ. 2021; 372: n309.

82. Jones I, Roy P. Sputnik V COVID-19 vaccine candidate appears safe and effective. Lancet. 2021; 397: 642-643.

83. Polack FP, Thomas SJ, Kitchin N, Absalon J, Gurtman A, Lockhart S, et al. Safety and efficacy of the BNT162b2 mRNA Covid-19 vaccine. N Engl J Med. 2020; 383: 2603-2615.

84. Baden LR, El Sahly HM, Essink B, Kotloff K, Frey S, Novak R, et al. Efficacy and safety of the mRNA-1273 SARS-CoV-2 vaccine. N EngI J Med. 2021; 384: 403-416.

85. Centers for Disease Control and Prevention. Interim clinical considerations for use of COVID-19 vaccines currently approved or authorized in the United States [Internet]. Atlanta, Georgia, U.S.: Centers for Disease Control and Prevention; 2022 [cited date 2022 January 17]. Available from: $\quad$ https://www.cdc.gov/vaccines/covid-19/clinical-considerations/covid-19-vaccinesus.html.

86. Duchini A, Goss JA, Karpen S, Pockros PJ. Vaccinations for adult solid-organ transplant recipients: Current recommendations and protocols. Clin Microbiol Rev. 2003; 16: 357-364.

87. Mulley WR, Dendle C, Ling JE, Knight SR. Does vaccination in solid-organ transplant recipients result in adverse immunologic sequelae? A systematic review and meta-analysis. J Heart Lung Transplant. 2018; 37: 844-852. 
88. Weimer R, Staak A, Susal C, Streller S, Yildiz S, Pelzl S, et al. ATG induction therapy: Long-term effects on Th1 but not on Th2 responses. Transpl Int. 2005; 18: 226-236.

89. Scharpe J, Evenepoel P, Maes B, Bammens B, Claes K, Osterhaus AD, et al. Influenza vaccination is efficacious and safe in renal transplant recipients. Am J Transplant. 2008; 8: 332-337.

90. Danziger-Isakov L, Kumar D. Vaccination of solid organ transplant candidates and recipients: Guidelines from the American society of transplantation infectious diseases community of practice. Clin Transplant. 2019; 33: e13563.

91. Boyarsky BJ, Werbel WA, Avery RK, Tobian AA, Massie AB, Segev DL, et al. Immunogenicity of a single dose of SARS-CoV-2 messenger RNA vaccine in solid organ transplant recipients. JAMA. 2021; 325: 1784-1786.

92. Cucchiari D, Egri N, Bodro M, Herrera S, Del Risco-Zevallos J, Casals-Urquiza J, et al. Cellular and humoral response after MRNA-1273 SARS-CoV-2 vaccine in kidney transplant recipients. Am J Transplant. 2021; 21: 2727-2739.

93. Embi PJ, Levy ME, Naleway AL, Patel P, Gaglani M, Natarajan K, et al. Effectiveness of 2-dose vaccination with mRNA COVID-19 vaccines against COVID-19-associated hospitalizations among immunocompromised adults - nine states, January-September 2021. MMWR Morb Mortal Wkly Rep. 2021; 70: 1553-1559.

94. Werbel WA, Boyarsky BJ, Ou MT, Massie AB, Tobian AA, Garonzik-Wang JM, et al. Safety and immunogenicity of a third dose of SARS-CoV-2 vaccine in solid organ transplant recipients: $A$ case series. Ann Intern Med. 2021; 174: 1330-1332.

95. Kamar N, Abravanel F, Marion O, Couat C, Izopet J, Del Bello A. Three doses of an mRNA Covid19 vaccine in solid-organ transplant recipients. N Engl J Med. 2021; 385: 661-662.

96. Stumpf J, Tonnus W, Paliege A, Rettig R, Steglich A, Gembardt F, et al. Cellular and humoral immune responses after 3 doses of BNT162b2 mRNA SARS-CoV-2 vaccine in kidney transplant. Transplantation. 2021; 105: e267-e269.

97. Benotmane I, Gautier G, Perrin P, Olagne J, Cognard N, Fafi-Kremer S, et al. Antibody response after a third dose of the mRNA-1273 SARS-CoV-2 vaccine in kidney transplant recipients with minimal serologic response to 2 Doses. JAMA. 2021; 326: 1063-1065.

98. Centers for Disease Control and Prevention. COVID-19 vaccines for moderately or severely immunocompromised people [Internet]. Atlanta, Georgia, U.S.: Centers for Disease Control and Prevention; 2022 [cited date 2022 January 16]. Available from: https://www.cdc.gov/coronavirus/2019-ncov/vaccines/recommendations/immuno.html.

99. American Society of Transplantation. COVID-19 vaccine FAQ sheet (updated 11/14/2021) [Internet]. NJ, USA: American Society of Transplantation; 2021 [cited date 2022 January 17]. Available from: https://www.myast.org/sites/default/files/11.14.21-VaccineFAQ-

Professionals.pdf.

100.AstraZeneca. Evusheld (formerly AZD7442) long-acting antibody combination authorised for emergency use in the US for pre-exposure prophylaxis (prevention) of COVID-19 [Internet]. Cambridge, UK: AstraZeneca; 2021 [cited date 2022 January 16]. Available from: https://www.astrazeneca.com/media-centre/press-releases/2021/evusheld-long-actingantibody-combination-authorised-for-emergency-use-in-the-us-for-pre-exposure-prophylaxisprevention-of-covid-19.html.

101.ClinicalTrials.gov. Phase III double-blind, placebo-controlled study of AZD7442 for postexposure prophylaxis of COVID-19 in adults (STORM CHASER) [Internet]. ClinicalTrials.gov; 2020 [cited date 2022 January 16]. Available from: https://clinicaltrials.gov/ct2/show/NCT04625972.

102.American Society of Transplantation. AST Statement on Use of Monoclonal Antibody for PreExposure Prophylaxis [Internet]. NJ, USA: American Society of Transplantation; 2021 [cited date 2022 January 17]. Available from: 
https://www.myast.org/sites/default/files/AST\%20Statement\%20on\%20Use\%20of\%20Monoc lonal\%20Antibody Final 0.pdf.

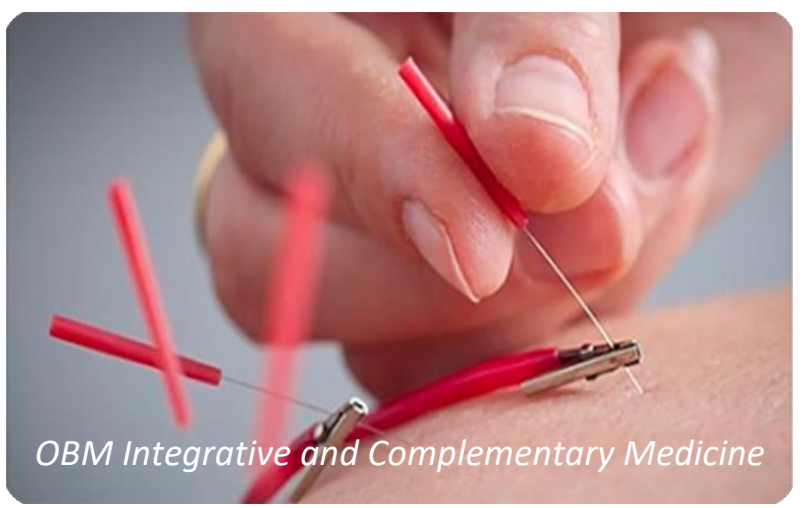

Enjoy OBM Integrative and Complementary Medicine by:

1. Submitting a manuscript

2. Joining in volunteer reviewer bank

3. Joining Editorial Board

4. Guest editing a special issue

For more details, please visit:

http://www.lidsen.com/journals/icm 